\title{
Nutcracker Syndrome as Unusual Cause of Hematuria in a young woman: A Case Report
}

\author{
Prof. Dr. Kemal Niyazi Arda ${ }^{1 *}$, Oğuz Han Karadenizli MD², Sinan Akay MD³ , Prof. Dr. Mesut Gürdal ${ }^{4}$
}

${ }^{1,2}$ University of Health Sciences, Gülhane Training and Research Hospital, Radiology Dept. Ankara / Turkey 06010

${ }^{3}$ University of Iowa, Department of Radiology, 200 Hawkins Drive Iowa City, IA 52242-1089 USA

${ }^{4}$ University of Health Sciences, Gülhane Training and Research Hospital, Urology Dept. Ankara / Turkey 06010

DOI: $10.36347 /$ simcr.2020.v08i12.014

| Received: 13.12.2020 | Accepted: 24.12.2020 | Published: 29.12.2020

*Corresponding author: Prof. Dr. Kemal Niyazi Arda

Abstract

Case Report

Nutcracker syndrome is an uncommon vascular compression disorder that is characterized by the compression of left renal vein between the abdominal aorta and superior mesenteric artery. It tends to occur in female patients with a predilection of third and fourth decades. Symptoms are non-specific and diagnose is possible with exclusion of more common causes and, with imaging studies. The diagnosis can be made with Doppler ultrasound, computed tomography angiography, magnetic resonance angiography and retrograd venography. We present a case with this rare syndrome diagnosed with computed tomography angiography. This entity can be easily overlooked unless it comes to mind and dedicated imaging is performed.

Key words: Nutcracker syndrome, computed tomography angiography, hematuria.

Copyright $\odot 2020$ The Author(s): This is an open-access article distributed under the terms of the Creative Commons Attribution 4.0 International License (CC BY-NC 4.0) which permits unrestricted use, distribution, and reproduction in any medium for non-commercial use provided the original author and source are credited.

\section{INTRODUCTION}

Hematuria may be a hint of an underlying disease, some of which are easily diagnosed and rest of them are required extensive workup. The causes vary according to age and gender, with the most common ones are inflammation/infection of the bladder or prostate, urinary stones, and, in elderly patients, urinary system malignancy or benign prostatic hyperplasia [1].

Nutcracker syndrome (NS) also known as left renal vein entrapment syndrome, is characterized by compression of the left renal vein between the abdominal aorta and superior mesenteric artery (SMA). This entity mostly is a rare cause of hematuria and presents with hematuria and pain although it may be asymptomatic [2]. Diagnosis is frequently delayed or missed, due to different manifestations of the syndrome and lack of consensus on diagnostic criteria [3].

\section{CASE REPORT}

A 28-year-old woman was referred to our clinic from another university hospital, with a history of intermittant gross hematuria and left flank pain of several months. She had no history of trauma or sexually transmitted diseases and there was no associated dysuria or fever. Physical examination was normal. She had low body mass index $\left(17.6 \mathrm{~kg} / \mathrm{m}^{2}\right)$. Urinalysis confirmed $3+$ blood cells without crystals or microorganisms. Ultrasound and cystoscopy could not detect any renal, ureteral, or bladder anomaly. Family and past medical histories were unremarkable. Complete blood count, routine biochemical tests, complement serology, anti-GBM antibodies, and bleeding parameters were within normal limits. Computed tomography angiography (CTA) revealed the external compression of left renal vein by the abdominal aorta and SMA (Figure 1,2). Considering patient's symptoms and radiological findings, NS was primarily assessed as the final diagnosis. The patient is given a diet to increase the abdominal fat volume.



Fig-1: On contrast enhanced axial CT image, narrowed left renal vein between abdominal aorta and superior mesenteric artery was seen (white arrowhead) 


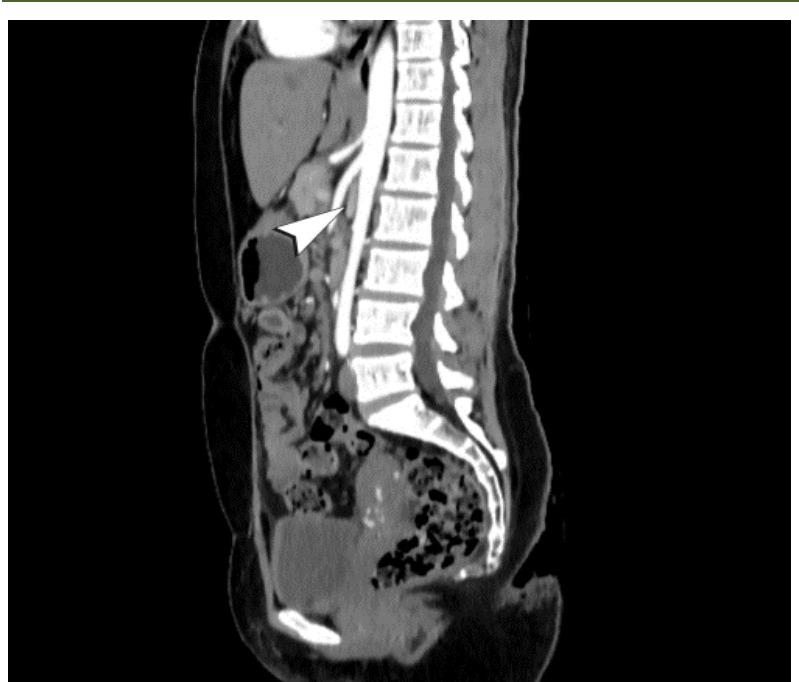

Fig-2: On contrast enhanced reconstructed sagittal CT image, decreased angle between abdominal aorta and superior mesenteric artery and compressed left renal vein between them (white arrowhead) were seen

\section{DISCUSSION}

Left renal vein entrapment syndrome, described as the compression of the left renal vein between the superior mesenteric artery and abdominal aorta was firstly mentioned in 1950 by El Sadr and Mina [4]. Chait et al. defined the abdominal aorta and SMA as the two components of a 'nutcracker' that may compress and narrow the left renal vein [5]. This term is credited by De Schepper denominating this phenomenon as NS [6].

The term "nutcracker syndrome" should not be used as an alternative to the term "nutcracker phenomenon" which is elementally the compression of the aortomesenteric portion of the left renal vein. This phenomenon is not link with clinical symptoms all the time and such anatomic findings that are reminder of nutcracker may exemplify a normal variant or be associated with other conditions. Hence, the term "nutcracker syndrome" should only be used for patients showing particular clinical symptoms connected to morphologic findings belong to nutcracker phenomenon [2]. A type of nutcracker syndrome occured when retroaortic left renal vein may be compressed between the abdominal aorta and vertebral column $[7,8]$.

Nutcracker phenomenon is often found incidentally in patients undergoing medical imaging for other purposes. NS is more frequently seen in young women with a predilection in third and fourth decades and our patient was 28 years old. This syndrome is typically seen in slim patients due to the narrowed angle between SMA and abdominal aorta (normal values ranging $38^{\circ}-65^{\circ}$ ) and a decrease in the distance between the abdominal aorta and SMA (normal values ranging $10-14 \mathrm{~mm}$ ) probably due to decrease in the volume of retroperitoneal and mesenteric fat tissue [9]. In our case, the patient was a slender woman and the angle and the distance between abdominal aorta and SMA were measured on CTA as $25^{\circ}$ and $9 \mathrm{~mm}$, respectively.

This syndrome is associated with varying spectrum of symptoms and findings from microscopic hematuria to progressive pelvic congestion, and, may be accompanied by left flank pain, gonadal vein syndrome and varicocele. Proteinuria may occur to some extent. Symptoms are frequently exacerbated with physical activity [2,10]. Hematuria is the most common symptom and mainly caused by rupture of intrarenal vessels owing to increased venous pressure, into the collecting system [11]. Varicoceles may develop secondary to elevated pressure in left renal vein which is regarded by Zerhouni et al. as the main reason for occurence of varicoceles in NS [13]. However, this findings was not found in our case.

It is obvious that the definitive diagnosis can not be reached without dedicated imaging studies. Making the diagnosis is also difficult due to ambiguous complaints attributable to a number of more common etiologies, like urinary stones [14]. To rule out more common renal conditions presents with hematuria and flank pain, various diagnostic studies can be performed such as routine blood tests, urinalysis, urine culture, cytology, urethrocystoscopy, intravenous pyelography, and renal biopsy [2].

Appropriate imaging modalities include CTA, Doppler ultrasound, magnetic resonance angiography and renal angiography. Intravenous pyelography may be used to show notching of the renal pelvis and ureters caused by varicosities. Cystoscopy may be show the bleeding from the left ureter [12]. Doppler ultrasound can provide additional information for the diagnosis, such as defining the dilated left renal vein and possible flow abnormalities [10]. In addition, magnetic resonance angiography may be used as an noninvasive option to demonstrate the narrow and dilated portions of left renal vein.

In our case, CTA revealed the distended portion proximal to the narrowed left renal vein between abdominal aorta and SMA. In the light of the symptoms of the patient and absence of more common etiologies, the diagnosis is established as NS. Conservative management is preferred and a diet plan is prepared to help patient to gain weight. Interventional radiology techniques using endovascular stents or surgery are the other treatment options for the patients who were not get benefit from the conservative treatment or with more severe and frequent symptoms [15].

\section{Concludsion}

It is important to be familiar with the diagnostic approach for NS, considering the high possibility of missing the diagnosis even in 
symptomatic patients. Renal vein thrombose and kidney injury might occur, if left untreated. The physicians should remind this syndrome, especially in the patients with hematuria of unkown origin and other suggestive symptoms when other routine diagnostic studies are inconclusive. Additionally, the radiologists should be familiar with the findings of this rare syndrome.

\section{REFERENCES}

1. Mariani AJ, Mariani MC, Macchioni C, Stams UK, Hariharan A, Moriera A. The significance of adult hematuria: 1,000 hematuria evaluations including a risk-benefit and cost-effectiveness analysis. J Urol. 1989;141(2):350-5.

2. Kurklinsky AK, Rooke TW. Nutcracker phenomenon and nutcracker syndrome. Mayo Clin Proc. 2010; 85(6): 552-9.

3. Waseem M, Upadhyay R, Prosper G. The nutcracker syndrome: an underrecognized cause of hematuria. European journal of pediatrics. 2012 Aug 1;171(8):1269-71.

4. EL-Sadr AR, Mina E. Anatomical and surgical aspects in the operative management of varicocele. Urol Cutaneous Rev. 1950; 54(5):257-62.

5. CHAIT A, MATASAR KW, FABIAN CE, MELLINS HZ. Vascular impressions on the ureters. American Journal of Roentgenology. 1971 Apr;111(4):729-49.

6. de Schepper A. Nutcracker" phenomenon of the renal vein and venous pathology of the left kidney. J Belge Radiol. 1972; 55(5):507-11.
7. Dunphy L, Penna M, Tam E, El-Kafsi J. Left renal vein entrapment syndrome: nutcracker syndrome! BMJ Case Rep. 2019;12(9):e230877.

8. Skeik N, Gloviczki P, Macedo TA. Posterior nutcracker syndrome. Vasc Endovascular Surg. 2011; 45(8):749-55.

9. Lamba R, Tanner DT, Sekhon S, McGahan JP, Corwin MT, Lall CG. Multidetector CT of vascular compression syndromes in the abdomen and pelvis. Radiographics. 2014 Jan;34(1):93-115.

10. Chen YM, Wang IK, $\mathrm{Ng} \mathrm{KK}$, Huang CC. Nutcracker syndrome: an overlooked cause of hematuria. Chang Gung Med J. 2002; 25(10):7005.

11. Nickavar A. Nutcracker syndrome; a rare cause of hematuria. Journal of Nephropathology. 2016;5(4):144-5.

12. Coolsaet BL. Ureteric pathology in relation to right and left gonadal veins. Urology. 1978; 12(1):40-9.

13. Zerhouni EA, Siegelman SS, Walsh PC, White RI. Elevated pressure in the left renal vein in patients with varicocele: preliminary observations. J Urol. 1980; 123(4):512-3.

14. Wang L, Yi L, Yang L, Liu Z, Rao J, Liu L, Yang J. Diagnosis and surgical treatment of nutcracker syndrome: a single-center experience. Urology. 2009; 73(4):871-6.

15. Ananthan K, Onida S, Davies AH. Nutcracker Syndrome: An Update on Current Diagnostic Criteria and Management Guidelines. Eur J Vasc Endovasc Surg. 2017; 53(6):886-894. 